\title{
REFLEXIVIDAD, EMANCIPACIÓN Y UNIVERSALISMO: CARTOGRAFÍAS DE LA TEORÍA DE LAS RELACIONES INTERNACIONALES
}

\author{
José Antonio SANAHUJA*
}

SUMARIO: 1. INTRODUCCIÓN: RELATOS CANÓNICOS, «GRANDES DEBATES»Y POSTPOSITIVISMO.-2. EL EJE EPISTEMOLÓGICO: RACIONALISMO-REFLECTIVISMO, POSITIVISMO-POST-POSITIVISMO.-3. EL EJE PRAXEOLÓGICO Y NORMATIVO: LA POSIBILIDAD Y DESEABILIDAD DEL CAMBIO.—4. LA CRÍTICA Y REDEFINICIÓN DE LO UNIVERSAL Y LO HUMANO: POSIBILIDADES DE UN UNIVERSALISMO POST-OCCIDENTAL.

\section{INTRODUCCIÓN: RELATOS CANÓNICOS, «GRANDES DEBATES» Y POST-POSITIVISMO}

El ascenso de los países emergentes, en particular en Asia, estaría dando paso a un sistema internacional que se ha descrito como multipolar, que cuestiona la primacía de Estados Unidos, y por ello también se ha caracterizado como «post-occidental», «post-hegemónico», o «post-estadounidense» ${ }^{1}$. Se trataría de un mundo en transición, sin una estructura o fisonomía clara, en una etapa que Thomas Friedman ha descrito como la "post-post-Guerra

* Profesor titular de Relaciones Internacionales de la Universidad Complutense de Madrid e investigador del Instituto Complutense de Estudios Internacionales (ICEI) (sanahuja@cps.ucm.es). El autor agradece los comentarios de Miren Alonso, Celestino del Arenal y Francisco Javier Verdes-Montenegro y de los dos revisores anónimos del manuscrito original.

1 Véanse, entre otros, ZaKaria, F., The Post-American World, Nueva York, W. W. Norton, 2008; MAHBubani, K., The New Asian Hemisphere. The Irresistible Shift of Global Power to the East, Nueva York, Public Affairs, 2009; y Acharya, A., The End of American World Order, Cambridge, Polity, 2014. En la doctrina española véanse ARENAL, C., «Mundialización, creciente interdependencia y globalización en las relaciones internacionales», Cursos de Derecho Internacional y Relaciones Internacionales de VitoriaGasteiz 2008, Bilbao, Universidad del País Vasco, 2009, pp. 181-268; García SEgura, C., "Westfalia, Worldfalia, Eastfalia. El impacto de las transformaciones de la estructura de poder interestatal en el orden internacional», Revista Española de Derecho Internacional, vol. LXIX, 2007, núm. 2, pp. 45-70; y SANAHUJA, J. A., «Posglobalización y ascenso de la extrema derecha: crisis de hegemonía y riesgos sistémicos», en MEsa, M. (coord.), Seguridad internacional y democracia: guerras, militarización y fronteras. Anuario 2016-17, Madrid, CEIPAZ, 2017, pp. 35-71. 
fría ${ }^{2}$. Con esa expresión se subraya que esta etapa es al menos tan difícil de caracterizar como la posterior a la Guerra Fría, por ello se insiste en el prefijo «post», ya que en ambos casos no existen conceptos, descripciones o metáforas claras y ampliamente aceptadas para describir el sistema internacional contemporáneo.

Esos cambios exigen revisar incluso los categorías y marcos interpretativos convencionales. El concepto mismo de «polaridad», por ejemplo, es problemático $^{3}$. Las dinámicas de globalización y transnacionalización que han transformado el sistema internacional han significado cambios rápidos en la estructura del sistema internacional, y en la naturaleza, las fuentes y las pautas de distribución del poder y la riqueza. Aparecen nuevos actores, pero su influencia se diluye en mercados, estructuras y redes de interdependencias que diluyen la polaridad, pues ningún actor parece tener primacía ni ejercer un control efectivo. De ahí que, frente a la imagen de un mundo multipolar, también se haya hablado de un mundo "multicéntrico», «interpolar»o "heteropolar», e incluso "apolar», del «G-cero», e incluso de «el fin del poder» ${ }^{4}$.

Estos cambios comportan un triple desafío intelectual y académico para la disciplina de las Relaciones Internacionales. Por una parte, exige examinar esas transformaciones estructurales en sí, desde una perspectiva sociohistórica; por otra, demanda teorías adecuadas para permitir su conceptualización e interpretación. Esto último supone, a su vez, adoptar una mirada crítica y reflexiva sobre las relaciones internacionales como objeto de estudio y sus principales teorías y conceptos, en particular hacia sus corrientes dominantes o mainstream. Ya no bastaría un conocimiento amplio de esas teorías, y se reclama una mirada crítica y reflexiva que permita entender su papel en la propia constitución de la disciplina y de los actores, prácticas, instituciones e ideas que son su objeto de estudio.

Este reclamo no es algo nuevo. La historia de las Relaciones Internacionales como disciplina se ha presentado tradicionalmente, de forma canónica y auto-referencial, a partir de los «grandes debates» que han surgido de la crítica entre los paradigmas dominantes, sea en sus expresiones clásicas o en las versiones más racionalistas o "científicas» ${ }^{5}$. Cabe mencionar el primer gran debate entre realismo e idealismo de las décadas de los años treinta y los cua-

\footnotetext{
2 Friedman, T., «The post-post-Cold War», The New York Times, 10 de mayo de 2016.

3 BARBÉ, E., «Multilateralismo: adaptación a un mundo con potencias emergentes», Revista Española de Derecho Internacional, vol. LXII, 2010, núm. 2, p. 25.

4 SANAHUJA, J. A., “¿Un mundo unipolar, multipolar o apolar? El poder estructural y las transformaciones de la sociedad internacional contemporánea», en VVAA, Cursos de Derecho Internacional y Relaciones Internacionales de Vitoria-Gasteiz. 2007, Bilbao, Universidad del País Vasco, 2008, pp. 297384; GREVI, G., «The interpolar world: a new scenario», EU-ISS occasional paper, 2009, núm. 79; CoPELAND, D., «Diplomacy, Globalization and Heteropolarity: The Challenge of Adaptation», Canadian Defence \& Foreign Affairs Institute Policy Paper, 2013; HAAS, R., "The age of non-polarity: What will follow US dominance?», Foreign Affairs, vol. 87, 2008, núm. 3, pp. 44-56; Kupchan, C. A., No One's World. The West, the Rising Rest, and the Coming Global Turn, Oxford, Oxford University Press, 2012; BREmmer, I., Every Nation for Itself: Winners and Losers in a G-Zero World, Londres, Portfolio/Penguin, 2012; NAím, M., El fin del poder, Barcelona, Debate, 2013.

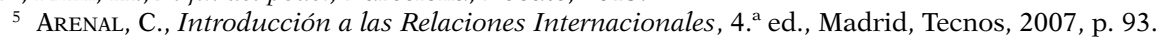


renta del siglo xx; un segundo gran debate entre tradicionalismo y cientifismo, en los años cincuenta y sesenta; y un tercer gran debate inter-paradigmático en los setenta y parte de los ochenta. En una versión muy extendida -en particular, en la Escuela Española- se presentó como debate a tres bandas entre el paradigma realista, transnacionalista o globalista, y estructuralista ${ }^{6}$. Esa tríada ha sido definida en diferentes términos y conceptualizaciones que no se abordarán aquí. Para Viotti y Kauppi, por ejemplo, podría definirse en términos de realismo, pluralismo y globalismo ${ }^{7}$; o de realismo, racionalismo y revolucionismo, según la Escuela Inglesa, o de las tradiciones de Maquiavelo, Grocio y Kant, según Martin Wight ${ }^{8}$.

Sin embargo, los debates inter-paradigmáticos son un equívoco relato auto-referencial de la disciplina, quizá solo válido en la fase final del periodo de Entreguerras; o bien cuando realmente hubo «tres» paradigmas: en el breve lapso de los años sesenta y setenta del siglo xx, y en ese periodo, en realidad, solo hubo debate entre el realismo y el liberalismo, con el estructuralismo en una posición marginal ${ }^{9}$. El debate que interesó al estructuralismo se ubicó en otro ámbito, el de la Economía Política Internacional y los estudios del desarrollo, en el que se enfrentó con la economía clásica o liberal dominante y con el paradigma sociológico de las teorías de la modernización.

Por otra parte, el debate inter-paradigmático puso de relieve un problema epistemológico esencial: la inexistencia de un postulado universal, teoría general o fundamento básico común («fundacional») a partir del cual juzgar cada paradigma, sus pretensiones de verdad, y establecer criterios para la verificación o falsación del conocimiento que pudieran generar. Las diferencias epistemológicas entre paradigmas harían imposible el diálogo y el supuesto de la acumulación lineal de conocimiento del positivismo, vía prueba y refutación dentro de una racionalidad común. Paul Feyerabend y Thomas Kuhn se han referido a este hecho aludiendo a la «inconmensurabilidad» entre teorías sin lenguaje o fundamento común ${ }^{10}$. Cada paradigma contaría con su propio sistema coherente de postulados fundamentales, ontologías, concep-

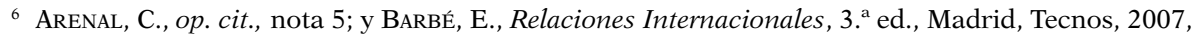
p. 60. Véase también García PiCAzo, P., Teoría breve de las Relaciones Internacionales ¿Una anatomía del mundo?, 5. ${ }^{a}$ ed., Madrid, Tecnos, 2017. Otros autores han preferido hablar de la hegemonía del realismo, y de "programas de investigación» — como los define Imre Lakatos— como el marxismo, el enfoque sistémico, de la dependencia, transnacionalista, y sociológico. Véase CALDUCH, R., Teorías de las Relaciones Internacionales, Madrid, Universidad Complutense, 2000, p. 67.

7 Viotti, P. R. y KaupPI, M. V., International Relations Theory: Realism, Pluralism, Globalism, 2. ed., Nueva York, Macmillan, 1993.

8 Wight, G. y Porter, B. (eds.), International theory: the three traditions. Martin Wight, Leicester/ Londres, Leicester University Press, 1991; BuzAN, B., An introduction to the English School of International Relations, Cambridge, Polity, 2004.

9 SмIтн, S., "The Self-Images of a Discipline: A Genealogy of International Relations Theory», en Воотн, K. у Sмітн, S. (eds.) International Relations Today, University Park, Penn State University Press, 1995, pp. 1-37.

10 Oberheim, E. y Hoyningen-Huene, P., «Inconmensurability, Realism, and Meta-Inconmensurability», Theoria. An International Journal for Theory, History and the Foundations of Science, vol. 12, 1997, núm. 3, pp. 447-465. 
tos y categorías, métodos, criterios de juicio, «semántica», y un patrón propio de inferencias de causalidad. Desde la asunción de la inconmensurabilidad, no sería factible afirmar la mayor validez "científica» de un paradigma y de sus postulados básicos sobre otro, como en el primer debate, por lo que tampoco se podría fundamentar la disciplina de las Relaciones Internacionales sobre un único corpus teórico coherente y "verdadero». Habría que aceptar el pluralismo teórico, con teorías distintas que veían mundos distintos, imposibles de integrar en "gran síntesis» y, por ello, con mayor riesgo de fragmentación. Sería, en consecuencia, una disciplina más rica, diversa y plural, pero envuelta en un «diálogo de sordos» o, más bien, en monólogos autorreferenciales. Por ello, según Wæver, el propio debate inter-paradigmático quizás pudo ser el "pegamento» que mantuvo mínimamente unida a la disciplina en ese periodo ${ }^{11}$.

Como es sabido, el debate inter-paradigmático dio paso en los años ochenta a la denominada "síntesis neo-neo" al producirse una visible convergencia entre el realismo estructural y el liberalismo. Con el realismo estructural de Waltz, quedó atrás la tradicional argumentación sobre la maldad inherente a la condición humana, como premisa ético-filosófica o religiosa básica del realismo clásico, de raíz judeo-cristiana, y se pretendió establecer una nueva fundamentación racional para que el realismo pudiera ser una verdadera teoría "científica» de la política internacional. El liberalismo, por su parte, asumiría los condicionantes estructurales o sistémicos y el interés nacional como guías racionales de las preferencias de los actores, dejando atrás los elementos normativos del idealismo, y recurriría en mayor medida a metodologías cuantitativas ${ }^{12}$. Esa común fundamentación racionalista y las convergencia de agendas y métodos de investigación permitirían superar las barreras de la inconmensurabilidad. Tanto el institucionalismo neoliberal como la teoría neorrealista de la estabilidad hegemónica se centrarían en el estudio de la cooperación y los regímenes internacionales como concreción de una "síntesis neo-neo» con la que se reconstruyó el discurso dominante en la disciplina ${ }^{13}$. Fuera de esa síntesis, otra reacción crítica al problema de la inconmensurabilidad, también desde la Economía Política Internacional, es el trabajo de Susan Strange, que, dentro de una epistemología positivista, reivindicaba a Feyerabend y planteaba aproximaciones más eclécticas como su «teoría del poder estructural» ${ }^{14}$.

11 WÆVER, O., «The Rise and Fall of the Inter-Paradigm Debate», en Smith, S., Booth, K. y ZALEWSKI, M. (eds.), International Theory: Positivism \& Beyond, Cambridge, Cambridge University Press, 1996, p. 149.

12 Como muestra, véase MoravcsiK, A., «Taking Preferences Seriously: A Liberal Theory of International Politics», International Organization, vol. 5, 1997, núm. 4, pp. 513-553.

13 Barbé, E. y Soriano, J. P., «Del debate Neorrealismo-Neoliberalismo a la (re)construcción del discurso dominante en Relaciones Internacionales», en Arenal, C. y Sanahuja, J. A., Teorías de las Relaciones Internacionales, Madrid, Tecnos, 2015, pp. 127-156.

${ }^{14}$ Strange, S., States and Markets, Londres, Pinter, 1988; Strange, S., "What Theory? The Theory in Mad Money», CSGR Working Paper, núm. 18/98, 1998; y Cox, R. W., "Take six eggs: Theory, finance and the real economy in the work of Susan Strange», en Cox, R. W. y SinclaIR, T. J., Approaches to World Order, Cambridge, Cambridge University Press, 1996, pp. 174-189. 
Ahora bien, para la comprensión de las cartografías contemporáneas de la disciplina el punto de partida obligado debiera ser otro: la revolución postpositivista que sacudió los cimientos de las Ciencias Sociales a finales de los setenta y en la década de los ochenta, más que la síntesis «neo-neo» o el debate inter-paradigmático que, en ese momento, según Ole Wæver, ya era «un mapa engañoso y una mala guía para introducir a los estudiantes en el debate» ${ }^{15}$.

El muchas veces citado discurso de Robert Keohane como presidente de la International Studies Association (ISA) ${ }^{16}$ estableció que el principal eje de debate se habría situado entre dos polos: el racionalismo - como fundamentación teórica común tanto del neorrealismo como del neoliberalismo institucional-, y el «reflectivismo» o interpretativismo, que incluiría tanto el constructivismo social emergente, como la filosofía post-moderna ${ }^{17}$. Este eje o línea de tensión definiría el llamado "cuarto debate» de la disciplina ${ }^{18}$. En el mismo hay disputas ontológicas - entre materialismo e idealismo, y entre individualismo y holismo o, en otros términos, entre agencia y estructura-, pero su dimensión más relevante se situaría, como se indicó, en el ámbito epistemológico ${ }^{19}$.

En no pocos aspectos ese eje racionalismo-reflectivismo expresaría también las posiciones del mainstream frente a la «insurgencia» teórica del postpositivismo. Al partir de la teoría del conocimiento, el post-positivismo ha supuesto un radical desafío epistemológico para las Ciencias Sociales, dando origen a una amplia teorización crítica.

Hacia los años noventa, sin embargo, las posiciones en ese eje habrían evolucionado desde la polarización inicial. Los extremos seguían siendo fácilmente reconocibles, con los seguidores más radicales del rational choice y de la modelización y las metodologías cuantitativas y «científicas», por el lado del racionalismo; y la negatividad post-estructuralista y deconstructivista y su recurso a la hermenéutica, en el otro extremo. Pero también se observaría un cierto rapprochement al aparecer posiciones intermedias más matizadas.

Como señaló Alexander Wendt, en realidad pocos autores ubicados en el mainstream teórico se identificarían ya con el positivismo clásico o con un

15 WÆVER, O., op. cit., nota 11, p. 149.

16 Keohane, R. O., «International Institutions: Two Approaches», International Studies Quarterly, vol. 32, 1988, núm. 4, pp. 379-396.

17 Hoffman, M., "Critical Theory and the Inter-Paradigm Debate», Millennium: Journal of International Studies, vol. 16, 1987, núm. 2, pp. 231-250. De manera más general, sobre el fin del «debate inter-paradigmático» y la redefinición de la disputa teórica desde los años noventa del siglo XX, véase LAPID, Y., «The Third Debate: On the Prospects of International Theory in a Post-Positivist Era», International Studies Quarterly, vol. 33, 1989, núm. 3, pp. 235-254.

18 Aunque para algunos autores, que obvian el debate entre concepciones tradicionales y «científicas», este sería el tercer debate y no el cuarto. Véase de nuevo LAPID, Y., op. cit., nota 17.

19 Véase SoduPE, K., La teoría de las Relaciones Internacionales a comienzos del Siglo XXI, Bilbao, Universidad del País Vasco, 2003, pp. 62-75; y CoRnAGo, N., "Materialismo e idealismo en la teoría crítica de las relaciones internacionales», Revista Española de Derecho Internacional, vol. LVII, 2005, núm. 2, pp. 665-693. 
racionalismo extremo como el de los modelos más formalizados del rational choice $^{20}$, más propios de la Ciencia Política o la Microeconomía. Por otro lado, las posiciones post-estructuralistas más extremas, que conocieron una notable expansión en el decenio de los ochenta al amparo de la filosofía postmoderna, no han logrado modificar su posición marginal. Los desarrollos más importantes se han producido en un terreno intermedio en el que, por un lado, las posiciones racionalistas han ido asumiendo la relevancia de la historia, las instituciones y las normas y otras estructuras sociales y culturales profundas, reconociéndose su papel constitutivo en las preferencias y la identidad de los actores. Por otro lado, la epistemología reflexivista común a distintas teorías se configura como un nuevo racionalismo que responde a las exigencias de una "modernidad reflexiva» que revisa y redefine en términos contemporáneos los propósitos emancipadores de la ilustración. Este terreno intermedio se desarrolla en mayor detalle en la sección posterior.

Al iniciarse el siglo XxI, el escenario de la teoría de las Relaciones Internacionales se habría vuelto más complejo y diverso, y por ello, sus cartografías no se limitan a la disputa epistemológica antes expuesta. En el seno de las corrientes dominantes o mainstream, eminentemente racionalistas o positivistas, y también dentro de las teorías críticas existen importantes diferencias ontológicas, epistemológicas y normativas que es necesario desentrañar. Para trazar esas cartografías y caracterizar las principales propuestas teóricas se puede partir de tres grandes divisorias o ejes que articulan el debate: en primer lugar, continúa vigente la divisoria epistemológica entre el racionalismo y el reflectivismo, con el racionalismo radical y la negación deconstructivista como polos extremos. En segundo lugar, se observa una línea de tensión que gira en torno a la posibilidad y deseabilidad del cambio en el orden social, lo que concierne a la dimensión normativa de la teoría. La tercera divisoria o línea de tensión alude a la definición de lo universal y en concreto al pretendido carácter universal del conocimiento frente a la naturaleza esencialmente contingente, histórica, contextual e intersubjetiva del mismo, y la posibilidad y necesidad de un universalismo no occidental. En esas tres divisorias, a su vez, subyace la línea o eje de tensión entre fundacionalismo y antifundacionalismo, tanto en el ámbito epistemológico como normativo. El cruce de estas líneas de tensión trazaría un espacio en varias dimensiones, que no puede ceñirse a los ejes de debate con los que se caracterizó el panorama de décadas anteriores.

\section{EL EJE EPISTEMOLÓGICO: RACIONALISMO-REFLECTIVISMO, POSITIVISMO-POST-POSITIVISMO}

La primera de estas líneas de tensión gira en torno a los fundamentos epistemológicos de la teoría, siguiendo la divisoria entre el positivismo y el

\footnotetext{
20 Wendt, A., Social Theory of International Politics, Cambridge, Cambridge University Press, 1999 , p. 39.
} 
post-positivismo y en particular el eje racionalismo-reflectivismo. Se trata de controversias que parten más de la Teoría o la Filosofía del Conocimiento que del campo de las Relaciones Internacionales. Si bien las teorías dominantes siguen ancladas en una fundamentación racionalista, para el conjunto de la disciplina puede hablarse, desde los 2000, de un "giro» reflectivista muy amplio, que ha supuesto tanto la asunción amplia de la reflexividad como fundamento epistemológico, como un amplio desarrollo de las teorías que desde ahí cuestionan las teorías convencionales o mainstream de la disciplina $^{21}$.

Este eje también es reflejo de una pugna entre el fundacionalismo epistemológico inherente a las teorías clásicas, y el antifundacionalismo epistemológico - más moderado o radical- de las teorías constructivistas y críticas. El fundacionalismo alude a la pretensión de establecer una fundamentación última o básica del conocimiento en un conjunto de certezas elementales y/o universales. A través de ellas las creencias sobre el mundo, así como los elementos de causación que fundamentan el conocimiento científico, podrían ser sometidos a prueba y evaluados como "verdaderos» o «falsos» desde un procedimiento y unos postulados «científicos» y objetivos, que con ello proporcionarían una suerte de cimientos comunes a la disciplina. De nuevo en términos epistemológicos, por antifundacionalismo se entendería aquella posición que asume que ningún postulado o pretensión de verdad puede ser probada como tal, al no existir ningún parámetro neutral, universal u «objetivo» para hacerlo, por lo que el conocimiento debe ser objeto de interpretación en función de su contexto social, histórico y contingente. Ese contexto es también el que proporciona los fundamentos causales sobre los que explicar la realidad social. En suma, la relevancia de la cuestión fundacionalismo/antifundacionalismo radica en que en última instancia es una discusión sobre las «causas últimas» de los fenómenos sociales, los patrones de inferencia de causalidad en cada teoría, y la existencia misma de dichas causas.

En directa relación con lo anterior, en este eje radica la distinción clave entre teorías explicativas y teorías constitutivas. Las primeras, que suelen tener carácter fundacionalista, pretenden situarse en algún lugar fuera de la realidad social y ser un mero reflejo «objetivo» de esta. En otros términos, parten de la conocida distinción positivista entre realidad y conocimiento, entendiendo este como algo "externo» a la realidad social y las relaciones sociales. El conocimiento se concibe como reflejo y/o explicación de esa realidad, entendida como parte de un mundo "natural» u objetivo que ha de ser explicado a partir de un fundamento racional o científico igualmente «objetivo». Estas asumen el enfoque típicamente positivista de la causalidad de las denominadas "teorías explicativas», y de sus razonamientos basado en variables dependientes, independientes e intervinientes, por citar las más comunes en ese tipo de teorización.

21 Hamati-Ataya, I., «Reflectivity, reflexivity, reflexivism: IR's “reflexive turn” —and beyond», European Journal of International Relations, vol. 19, 2012, núm. 4, pp. 669-694. 
Frente a ellas, a partir de una epistemología reflectivista, se alzarían las "teorías constitutivas», que más que buscar relaciones de causalidad objetivables, tratarían de dar cuenta de la naturaleza de las relaciones internacionales a partir de las estructuras que las constituyen y las condicionan $^{22}$. Las teorías constitutivas entienden las teorías de las Relaciones Internacionales como elementos que constituyen la realidad social a través del conocimiento que estas generan, y de las instituciones, las prácticas sociales, el lenguaje y los discursos y narrativas a las que ese conocimiento daría forma ${ }^{23}$. Para estas teorías el conocimiento está enraizado en las relaciones sociales y es parte de ellas. Tiene un papel constitutivo de esa misma realidad, en tanto otorga significado a las relaciones sociales y orienta las prácticas de los actores sociales, construyendo el mundo conforme a la comprensión e interpretación del mismo por parte de esos actores. En este tipo de razonamiento, la cuestión de la causalidad se inscribe en la relación de mutua interacción y constitución entre la agencia y las estructuras sociales, atendiendo a sus componentes materiales, institucionales e ideacionales $^{24}$.

Las teorías constitutivas, además, se basan en la premisa kantiana de que un propósito esencial del conocimiento ha de ser la reflexión sobre los límites y condicionantes del mismo, y el aporte de Hegel y Marx de que el conocimiento está siempre e inevitablemente condicionado por el contexto y las condiciones sociales, materiales e históricas en el que se genera. Responde también al método hermenéutico de la Escuela de Fráncfort, y de manera más cercana está fuertemente influida por el trabajo sociológico de Pierre Bourdieu, Niklas Luhman o Ulrich Beck. Supone asumir que estudiar y teorizar la realidad social puede ser, debiera ser, y necesariamente es un acto reflexivo ${ }^{25}$.

22 Véase el trabajo pionero de Hollis, M. y SмITH, S., Explaining and Understanding International Relations, Oxford, Oxford University Press, 1990, y posteriormente WENDT, A., «On Constitution and Causation in International Relations», Review of International Studies, vol. 24, 1998, pp. 101-117, y KURKI, M., Causation in International Relations, Cambridge, Cambridge University Press, 2008.

${ }^{23}$ Véase Wight, C., "Philosophy of Social Science and International Relations», en CARLSNAES, W., Risse, T. y Simmons, B. A., Handbook of International Relations, Londres, SAGE, 2008, pp. 38-39.

${ }^{24}$ WENDT, A., "The Agent-Structure Problem in International Relations Theory», International Organization, vol. 41, 1987, núm. 3, pp. 335-70; CARLSNAES, W., «The Agency-Structure Problem in Foreign Policy Analysis», International Studies Quarterly, vol. 36, 1992, núm. 3, pp. 245-270; Wight, C., Agents, Structures and International Relations. Politics as Ontology, Cambridge, Cambridge University Press, 2006; KNAFO, S., "Critical approaches and the legacy of the agent/structure debate in international relations", Cambridge Review of International Affairs, vol. 23, 2010, núm. 3, pp. 493-516; y CABALLERO, S., «El debate agencia-estructura en las Relaciones Internacionales: capacidad de agencia y limitaciones estructurales», en VVAA, Otras miradas y otras voces. Visiones críticas de las Relaciones Internacionales, Buenos Aires, Eduntref, 2018 (en prensa).

25 Neufeld, M., «Reflexivity in International Relations Theory», Millennium: Journal of International Studies, vol. 22, 1993, núm. 1, pp. 53-76; LEANDER, A., «Do We Really Need Reflexivity in IPE? Bourdieu's Two Reasons for Answering Affirmatively», Review of International Political Economy, vol. 9, 2002, núm. 4, pp. 601-609; EAgleton-Pierce, M., «Advancing a Reflexive International Relations», Millennium - Journal of International Studies, vol. 39, 2011, núm. 3, pp. 805-823; y AdLER-NIELSSEN, R. (ed.), Bourdieu in International Relations. Rethinking Key Concepts in International Relations, Milton Park, Routledge, 2013. 
Mientas que las teorías explicativas, inscritas en la tradición positivista, pretenden proporcionar una explicación o explanans racional y con fundamentación empírica de la sociedad internacional, para las segundas la propia teoría es parte de esa realidad social, histórica y contingente. Como explanandum, es un fenómeno social más que ha de ser explicado a partir de una teorización interpretativista, en la tradición de la verstehen weberiana. Esta última exige lo que Anthony Giddens denomina la «doble hermenéutica» que ha de caracterizar las Ciencias Sociales, que de esta forma se distinguen de las Ciencias Naturales: los seres humanos interpretan el mundo a través de su reflexión, de sus prácticas, y de sus relaciones sociales; las Ciencias Sociales han de interpretar, a su vez, esas interpretaciones ${ }^{26}$. Puede añadirse que adoptar una mirada reflexiva implicaría también el examen crítico y la interpretación de la propia práctica académica dentro de esa «doble hermenéutica», examinando críticamente el papel de las normas, instituciones, actores y mecanismos de validación del conocimiento generado por la disciplina de las Relaciones Internacionales ${ }^{27}$.

Por otro lado, es importante precisar que el antifundacionalismo epistemológico no implica necesariamente asumir una posición relativista en el ámbito normativo. Como se verá, la teoría puede caracterizarse por un fundacionalismo normativo mínimo y contingente, respetuoso de la diversidad, basado en acuerdos surgidos de la acción comunicativa a través de la deliberación racional y de la propia actividad política. Ello puede fundamentar una ética del discurso universalista con propósitos de emancipación humana. Así lo afirma, por ejemplo, la Escuela Inglesa en su vertiente más solidarista o normativa, influida por Habermas; o la propia teoría crítica inspirada por ese autor $^{28}$.

Como se indicó, en este eje se ubicarían en el extremo positivista las variantes del liberalismo o el institucionalismo basadas en las premisas de la elección racional o rational choice, con un alto grado de formalización metodológica y el recurso frecuente a métodos cuantitativos. En el otro extremo de este eje encontraríamos el post-estructuralismo, el pensamiento decolonial, y la teoría feminista de las Relaciones Internacionales, que en cuanto a opciones metodológicas suelen recurrir a la hermenéutica y a otros métodos cualitativos como el análisis del discurso. Pero ambos polos, como se señaló, se situarían en una posición relativamente excéntrica y radical respecto a un mainstream en el que las teorías clásicas basadas en premisas racionalistas

26 Giddens, A., Social Theory and Modern Sociology, Cambridge, Polity Press, 1982, pp. 20-21, y The Construction of Society, Cambridge, Polity, 1984, p. 20. Véase también JACKson, P. T., «Making sense of Making Sense: Configurational Analysis and the Double Hermeneutic», en YANOw, D. y ScHWARTZSEA, P. (eds.), Interpretation and Method: empirical research methods and the interpretive turn, Londres, M. E. Sharpe, 2006, pp. 264-280

27 Jørgensen, K., Alejandro, A., Reichwein, A., Röch, F. y Turton, H., Reappraising European IR Traditions, Londres, Palgrave Macmillan, 2017, pp. 31-42.

28 Véase Hurrell, A., On Global Order. Power, values and the Constitution of the International Society, Oxford, Oxford University Press, 2007, pp. 300 y ss.; y LinKLATER, A., Critical Theory and World Politics. Citizenship, sovereignty and humanity, Milton Park, Routledge, 2007. 
se habrían desplazado hacia posiciones más moderadas y más reflexivas, al asumir la relevancia de la historia, las instituciones y las normas y otras estructuras sociales y culturales profundas, reconociendo su papel constitutivo en las preferencias y la identidad de los actores. Este sería el caso de un realismo neoclásico que se distanciaría del rígido racionalismo y del determinismo estructural del neorrealismo de Waltz ${ }^{29}$, o de la «Escuela Inglesa» de la Sociedad Internacional ${ }^{30}$.

En ese terreno intermedio la epistemología reflexivista ha dado lugar a un nuevo «racionalismo moderado» con voluntad y capacidad de convertirse en una corriente dominante en la disciplina, aun manteniendo cierta capacidad crítica sobre otros enfoques convencionales. Así lo mostraría la creciente aceptación del social-constructivismo, precisamente por combinar una fundamentación reflectivista con métodos y diseños de investigación racionalis$\operatorname{tas}^{31}$. En alguna de sus variantes, como la que representa Peter Kazenstein, el social-constructivismo muestra una vocación sociológica que a partir del método histórico-comparativo aborda el estudio de la identidad y de otros factores socio-culturales y civilizacionales ${ }^{32}$.

Aún en ese terreno intermedio, este eje abarca la teoría crítica neo o post-marxista, de nuevo sobre premisas epistemológicas post-positivistas, que se distancia de las pretensiones cientifistas del marxismo clásico y trata de responder a las exigencias de una «modernidad reflexiva» que revisa y redefine en términos contemporáneos los propósitos emancipadores de la ilustración. Expresa de nuevo un reflectivismo "post-radical» que aúna la reflexividad y el interpretativismo con un mayor reconocimiento de elementos materiales, de la sociología histórica, y del papel de las normas y las instituciones.

29 Rose, G., "Neoclassical Realism and Theories of Foreign Policy», World Politics, vol. 51, 1998, núm. 1, pp. 144-172; y Lobell, S., Ripsman, N. y TAliaferro, J., «Introduction: Neoclassical Realism, the State, and Foreign Policy», en ibid. (eds.), Neoclassical Realism, the State, and Foreign Policy, Nueva York, Cambridge University Press, 2009, pp. 1-41.

30 Desde el pluralismo del texto clásico de Bull, H., The Anarchical Society. A Study of order in World Politics, Londres, Macmillan, 1977, al enfoque normativo influido por Habermas y Linklater de Hurrell, A., op. cit., nota 28. También Buzan, B., From International to World Society? English School Theory and the Social Structure of Globalisation, Cambridge, Cambridge University Press, 2004; y García SEgura, C., "La Escuela Inglesa y la teoría de la Sociedad Internacional: propuestas, críticas y reformulación", en Arenal, C. y SANAHUJA, J. A., op. cit., nota 13, pp. 269-300.

31 AdLER, E., «Seizing the Middle Ground: Constructivism in World Politics», European Journal of International Relations, vol. 3, 2007, núm. 3, pp. 319-363; GuzzINI, S., «A Reconstruction of Constructivism in International Relations», European Journal of International Relations, vol. 6, 2000, núm. 2, pp. 147-182; Finnemore, M. y SiKkinK, K., "Taking Stock: The Constructivist Research Program in International Relations and Comparative Politics», Annual Review of Political Science, vol. 4, 2001, pp. 391-416; e IBÁÑEZ, J., "Socialconstructivismo: ideas, valores y normas en la política mundial», en Arenal, C. y Sanahuja, J. A., op. cit., nota 13, pp. 189-218.

32 Ejemplos clásicos de ello son WendT, A., "Anarchy is What States Make of It: The Social Construction of Power Politics», International Organization, 1992, núm. 46, pp. 391-425; y KatZENSTEIN, P. J. (ed.), The Culture of National Security, Nueva York, Columbia University Press, 1996. Véase también SANTA-CRUZ, A., «Introducción: Peter J. Katzenstein: la política sin fronteras o la ubicuidad de lo distintivo», en ibid. (ed.), La política sin fronteras. Ensayos escogidos de Peter J. Katzenstein, México, CIDE, 2002, pp. 13-36. 
Este rapprochement también se observa en dos tendencias relacionadas entre sí, y que son visibles desde los años noventa: el desarrollo de las teorías intermedias o de rango medio -middle range o mid-level theory-, y el frecuente recurso a marcos interpretativos basados en el pluralismo teórico y el eclecticismo metodológico. Ambas tendencias responden a la necesidad de abordar problemas específicos de las relaciones internacionales, de ampliar la capacidad explicativa del análisis de esos problemas, y de participar en el debate de política pública. También permiten evitar la "heurística negativa», en términos de Lakatos, que impone la adscripción estricta a un paradigma o teoría coherente y cerrada, o el aislamiento academicista propio de un debate teórico alejado de la práctica de las relaciones internacionales y la política exterior $^{33}$.

Según Sil y Katzenstein, un enfoque ecléctico es aquel que pretende elucidar, traducir e integrar selectivamente elementos de análisis, conceptos, lógicas, mecanismos e interpretaciones procedentes de teorías desarrolladas dentro de paradigmas diferenciados, pero que abordan problemas substantivos que tienen significación tanto desde el punto de vista académico como práctico. A menudo parten de la forma en la que esos problemas son entendidos y experimentados por los actores políticos, sin atarse a las exigencias ontológicas y epistemológicas de las "grandes teorías»(Grand Theory), reconociendo sus dificultades o, quizás, su «imposibilidad» en tiempos de globalización, como afirma Andreas Behnke ${ }^{34}$. La investigación enmarcada en un determinado paradigma generalmente aborda las cuestiones que forman parte de su particular problemática, y asume la primacía ontológica y causal de determinadas premisas y fenómenos. Por ello, ese eclecticismo podría plantear contradicciones teóricas, metateóricas y epistemológicas, así como discordancias desde el punto de vista ontológico. Pero esas inconsistencias pierden relevancia en la medida que el análisis se centra en asuntos específicos a resolver y se distancia de las cuestiones propias de las grandes teorías manteniendo, al tiempo, un alto nivel de exigencia y rigor analítico y conceptual $^{35}$.

Las teorías intermedias, o de rango medio, son aquellas que, orientadas a cuestiones concretas o issue-oriented, enlazan la "Gran Teoría» con problemáticas específicas de las relaciones internacionales, y en ocasiones se caracterizan también por cierto grado de eclecticismo y flexibilidad desde el punto de vista teórico y metodológico, aunque solo puedan dar lugar a gene-

33 Sil, R. y Katzenstein, P. J., Beyond Paradigms. Analytical Eclecticism and the Study of World Politics, Londres, Palgrave Macmillan, 2010; CHeckel, J. T., "Theoretical Synthesis in IR: Possibilities and Limits», Simons Papers in Security and Development, núm. 6/2010; y SørEnSEN, G., "The Case for Combining Material Forces and Ideas in the Study of IR», European Journal of International Relations, vol. 14, 2008, núm. 1, pp. 5-32. Sobre la combinación de métodos racionalistas e interpretativistas véase YANOW, D. y SCHWARTZ-SEA, P., op. cit., nota 26.

34 BehnKe, A., "Grand Theory in the Age of its Imposibility», en GuzzInI, S. y Leander, A. (eds.), Constructivism and International Relations. Alexander Wendt and his Critics, Londres, Routledge, 2006, pp. $48-56$

35 SiL, R. y Katzenstein, P. J., op. cit., nota 33, 2010, p. 10. 
ralizaciones contingentes y/o condicionadas ${ }^{36}$. Son ampliamente utilizadas por su valor heurístico, su capacidad de definir un programa de investigación "progresivo», en el sentido de Lakatos, y de orientar la investigación empírica. La teoría de juegos, y su recurso a métodos cuantitativos (Axelrod, Snidal); los modelos de toma de decisiones y el análisis de política exterior centrado en los actores (Allison, Jervis), o la «teoría de la paz democrática» (Doyle, Ray, Russett) serían ejemplos tempranos de este tipo de teorización. Desde los noventa, sin embargo, se han ampliado como resultado de las tendencias antes mencionadas. Ejemplos de este tipo de teorías, que se situarían de nuevo en esos espacios intermedios en el eje epistemológico, sería la teoría de los complejos regionales de seguridad, combinando elementos constructivistas, geopolítica, y el análisis realista de equilibrios de poder $^{37}$; la securitización ${ }^{38}$; los estudios sobre «europeización» de políticas, con aportes institucionalistas y socialconstructivistas ${ }^{39}$; o las teorías sobre «difusión» de instituciones y normas internacionales que parten de esas mismas premisas y también recurren a los métodos cuantitativos frecuentes en Ciencia Política ${ }^{40}$.

Sin perjuicio del importante desarrollo de la teoría y la creciente asunción de la reflexividad en ese espacio intermedio del eje de tensión epistemológico se han producido también amplios desarrollos en el polo del reflexivismo radical, a través del pensamiento decolonial y postcolonial —que se aborda con más detalle en una sección posterior-, y en particular las

36 LAKE, D., «Theory is dead, long live theory: the end of the Great Debates and the rise of eclecticism in International Relations», European Journal of International Relations, vol. 19, 2013, núm. 3, pp. 567-587.

37 Buzan, B. y WÆVer, O., Regions and Powers: The Structure of International Security, Cambridge, Cambridge University Press, 2003; Frazier, D. y STEWART-INGERsoll, R., «Regional powers and security: A framework for understanding order within regional security complexes», European Journal of International Relations, vol. 16, 2010, núm. 4, pp. 731-753; y de los mismos autores, Regional Powers and Security Orders. A theoretical Framework, Londres, Routledge, 2012.

38 Buzan, B., WÆVER, O. y DE WILDE, J., Security: a new framework for analysis, Londres, Lynne Rienner Publishers, 1998; Verdes-Montenegro, F. J., «Securitización: agendas de investigación abiertas para el estudio de la seguridad», Relaciones Internacionales, 2015, núm. 29, pp. 133-153; PÉREZ DE ArmiÑo, K., "Estudios de Seguridad: de la visión tradicional a los enfoques críticos», en ArEnAL, C. y SANAHUJA, J. A., op. cit., nota 13, pp. 301-328.

39 Véanse Green Cowles, M., CAPORAso, J. y Risse, T. (eds.), Transforming Europe: Europeanisation and Domestic Change, Ithaca, Cornell University Press, 2001; Featherstone, K. y Radaelli, C. (eds.), The Politics of Europeanization, Oxford, Oxford University Press, 2003; HiLl, C. y Wong, R. (eds.), National and European Foreign Policies: Towards Europeanisation, Londres, Routledge, 2011; y RUANO, L. (ed.), The Europeanization of National Foreign Policies Towards Latin America, Londres, Routledge, 2013.

40 Finnemore, M. y SIKKINK, K., "International Norm Dynamics and Political Change», International Organization, vol. 52, 1998, núm. 4, pp. 887-917; Simmons, B., DobBin, F. y GarretT, G., «Introduction: The International Diffusion of Liberalism», International Organization, vol. 60, 2006, núm. 4, pp. 781-810; GILARDI, F., "Transnational Diffusion: Norms, Ideas, and Policies», en CarLSNAES, W., Risse, T. y Simmons, B. A., op. cit., nota 23, pp. 453-502; Graham, E. R., Shipan, C. R. y Volden, C., "The Diffusion of Policy Diffusion Research in Political Science», British Journal of Political Science, vol. 43, 2013, núm. 3, pp. 673-701; BöRzel, T. A. y HüLlen, V. (eds.), Governance Transfer by Regional Organizations. Patching Together a Global Script, Londres, Palgrave Macmillan, 2015; y RISSE, T., «The Difussion of Regionalism», en BöRzEL, T. A. y Risse, T. (eds.), The Oxford Handbook of Comparative Regionalism, Oxford, Oxford University Press, 2016, pp. 87-108. 
teorías feministas de las Relaciones Internacionales. Estas teorías siguen afirmando la naturaleza histórica, contingente, contextual e intersubjetiva de la realidad social, y que el conocimiento que se genera en ese contexto, en tanto acto intersubjetivo, puede entenderse como una práctica social más y en particular, como la más relevante fuente de poder. Este, como advertiría Foucault, depende en última instancia del conocimiento; esto es, de la producción socialmente difusa de significados intersubjetivos y del establecimiento de «regímenes de verdad». Para este polo crítico - y esta es otra divisoria importante- ese planteamiento epistemológico también comporta el cuestionamiento de los confines, objeto y agendas de la disciplina de las Relaciones Internacionales, en la medida que suponen prácticas de silenciamiento y exclusión de saberes, actores, problemáticas, y resistencias que deberían ser objeto de atención.

Un claro ejemplo de ello son las teorías feministas de las Relaciones Internacionales. Estas teorías tratarían de desvelar la naturaleza androcéntrica y hetero-patriarcal de la producción de conocimiento, de las ontologías y conceptos centrales de las relaciones internacionales y de la disciplina misma ${ }^{41}$, lo que se ha encontrado con el rechazo y en ocasiones la incomprensión de las teorías dominantes ${ }^{42}$. Para estas teorías el género, además de ser variable analítica, se configura como elemento constitutivo de las relaciones sociales, incluyendo las relaciones internacionales. Parte así de una epistemología reflectivista informada por el feminismo y el enfoque de género, asumiendo que el conocimiento es reflejo de unas relaciones sociales determinadas por el patriarcado y la desigualdad de género, y contribuye, a su vez, a su reproducción y sostenimiento. Según Cynthia Enloe, se debe partir de la posición y la experiencia de las mujeres en las relaciones internacionales y del hecho fundamental de que apenas están presentes en los lugares en los que estas se teorizan y se llevan a la práctica: las cancillerías, los ejércitos, las fuerzas de seguridad o la academia ${ }^{43}$. Una epistemología desde el punto de vista feminista (feminist standpoint), como la elaborada por la primera generación de autoras de estas teorías, debe buscar en otra parte: en la vida y experiencia de las mujeres y en su posición subordinada y excluida y aparentemente banal. Ello permitirá alumbrar espacios, actores, sujetos y cuerpos, así como estructuras y relaciones que la disciplina excluye, silencia o ignora. Con ello se alcanzará una comprensión más amplia del sistema internacional más allá de la mirada del "guerrero» y el «hombre de Estado», la política exterior y el «interés nacional». Como señala Jacqui True, el conocimiento que emerge de las experiencias de las mujeres «en los márgenes» de la política mundial es

\footnotetext{
41 Entre otros, Peterson, V. S., «Transgressing Boundaries: Theories of Knowledge, Gender, and International Relations», Millennium: Journal of International Studies, vol. 21, 1992, núm. 2, pp. 183192, y Hooper, C., Manly States: Masculinities, International Relations, and Gender Politics, Nueva York, New York University Press, 2000.

${ }^{42}$ Véase la crítica de TickneR, J. A., "You Just Don't Understand! Troubled engagements between Feminist and IR Theorists», International Studies Quarterly, vol. 41, 1997, núm. 4, pp. 611-632.

43 Como aportación pionera véase Enloe, C., Bananas, Beaches and Bases: Making Feminist Sense of International Politics, Berkeley, University of California, 1989.
} 
más neutral y crítico al no ser tan cómplice de, o ciego con las instituciones y relaciones de poder existentes ${ }^{44}$.

La teoría feminista, desde esta particular posición epistemológica, ha realizado importantes aportes a la Economía Política Internacional crítica y a los Estudios de Seguridad, que han permitido problematizar los conceptos económicos dominantes y las lógicas de producción, reproducción y mercantilización subyacentes, y examinar desde el punto de vista de género ontologías aparentemente neutras como «guerra», "Estado», "soberanía», "territorio», o "seguridad nacional», en la medida que se relacionan con prácticas que generan inseguridad para las personas y en particular para las mujeres. Ello supone revisar la relación entre las mujeres y la guerra, viendo esta última como categoría y práctica construida que, para ser inteligible, exige un enfoque crítico de género que examine la división sexual de la violencia, o los discursos androcéntricos de lo bélico ${ }^{45}$. Finalmente, supondría la revisión crítica del proyecto de la modernidad o «modernidad reflexiva» desde una perspectiva feminista, develando cómo esta es también resultado de una construcción androcéntrica.

\section{EL EJE PRAXEOLÓGICO Y NORMATIVO: LA POSIBILIDAD Y DESEABILIDAD DEL CAMBIO}

La deseabilidad y posibilidad del cambio en el orden internacional y, por ende, en el orden social, así como el papel de la teoría en los proyectos emancipatorios, son los elementos que definen una segunda divisoria o línea de tensión que atraviesa la teoría de las Relaciones Internacionales. Es la existente entre las teorías críticas y las que son funcionales al mantenimiento del orden y sus dinámicas de subordinación y exclusión. Se trata de la conocida distinción de Robert W. Cox entre las teorías que solventan los problemas o desajustes del orden social dominante (problem-solving theory), y aquellas que son críticas con dicho orden (critical theory) ${ }^{46}$. Estas últimas pretenden «desnaturalizar» dicho orden mostrando su carácter contingente e histórico; supone también situar las teorías de las Relaciones Internacionales en su contexto social e histórico — como se indicó, considerándolas más un explanandum que un explanans, es decir, más como realidades sociales que han de ser explicadas, que como explicaciones a validar o refutar conforme a premisas positivistas-, mostrando cómo están enraizadas en ese contexto y son funcionales al mantenimiento del orden, o su cuestionamiento. Por ello,

\footnotetext{
44 True, J. (2005), «Feminism», en Burchill, S., Devetak, R., Linklater, A., Paterson, M., Reus-Smit, C. y True, J., Theories of International Relations, Basingstoke, Palgrave Macmillan, 2001, p. 215.

45 Tickner, J. A., Gender in International Relations: Feminist Perspectives on Achieving International Security, Nueva York, Columbia University Press, 1992; ElshtaIn, J. B., Women and War, Chicago, University of Chicago Press, 1995.

46 Cox, R. W., "Social Forces, States and World Orders: Beyond International Relations Theory», Millennium: Journal of International Studies, vol. 10, 1981, núm. 2, p. 128.
} 
partirá de metodologías interpretativistas basadas, en diferente grado, en la sociología histórica y la hermenéutica.

Las teorías críticas, por ello, impugnan las lógicas internas de las teorías dominantes, y ello alude tanto a aquellas que carecen de fundamentación racional y se basan en principios metafísicos o metateóricos ajenos a la razón para justificar el orden vigente, como a aquellas otras que, habiendo surgido del proyecto racional de la modernidad, han terminado legitimando la inevitabilidad y/o deseabilidad de un determinado orden social ${ }^{47}$. Entre las primeras cabría mencionar al realismo clásico y su esencialismo metafísico sobre la maldad inherente al ser humano. Respecto a las segundas, las teorías críticas cuestionan el «movimiento lineal» y supuesta inevitabilidad que caracteriza a las teleologías cientifistas de la modernidad, como el marxismo clásico o el liberalismo institucional, como teorías que legitiman un orden social - tanto en su dimensión explicativa como prescriptiva- en nombre de un futuro o un presente que se concibe como un imperativo racional y que tendría validez universal. También sería el caso del concepto determinista de anarquía del neorrealismo de Kenneth Waltz, o las premisas del homo œconomicus de las teorías de la elección racional. Se rechazarían, en particular, el realismo o el neorrealismo ya que priorizan una visión estática y determinista que cierra el paso a toda posibilidad de cambio en las relaciones internacionales, o reduce este al cambio en el sistema interestatal de equilibrios de poder, sin que pueda imaginarse siquiera el cambio de dicho sistema. De igual manera, se cuestionarán las teleologías liberales que afirman la racionalidad del mercado como mecanismo de regulación social, y la viabilidad y necesidad de la democracia liberal dentro del mismo, al estilo de la tesis de «fin de la historia» de Francis Fukuyama.

Lo relevante en este caso no se sitúa en el ámbito epistemológico, sino praxeológico y normativo. Aun teniendo distinta fundamentación, las teorías clásicas terminan afirmando que existen unos principios básicos que explican la conducta humana y cimentan el orden social; que estos son inmutables, inevitables, de validez universal y no se ven alterados por el devenir de la historia. Por ello, cualquier posibilidad de agencia y de horizonte de cambio para la acción colectiva queda subordinada a esos principios, entendidos como determinantes, y algunas teorías, como el realismo clásico o el realismo estructural, incluso niegan ex-ante esas posibilidades.

Frente a ello, las teorías críticas se erigen como teorías eminentemente constitutivas; en el plano ontológico, asumen la naturaleza esencialmente social de la realidad, construida a través de la interacción y la comunicación humana, y no «dada» u objetiva, y el carácter contingente e histórico del orden social. En el plano praxeológico y normativo, afirmarán la posibilidad y deseabilidad de la acción colectiva dentro de un renovado proyecto ilustra-

47 Véanse, entre otros, Hoffman, M., op. cit., nota 17; Wyn-Jones, R. (ed.), Critical Theory and World Politics, Boulder, Lynne Rienner, 2001; DevetaK, R., "Critical Theory», en BurchiLl, S. et al., nota 44, pp. 155-180. 
do de emancipación. Ello, no obstante, exige revisar reflexivamente ontologías clave de la modernidad, como el Estado, la soberanía, la ciudadanía y la democracia en la medida que, alejadas de sus propósitos originales, ahora se configuran como mecanismos de exclusión, injusticia y subordinación; y porque en vez de ser instrumentos de la acción colectiva para promover el imperativo racional de la emancipación humana, cumplen la función opuesta, subordinado a la persona a los imperativos del mercado global, o del poder de determinados actores dominantes.

Estas dimensiones de la teorización crítica serían abordadas, en particular, por las teorías neo o post-marxistas posteriores a los años ochenta en sus dos grandes vertientes: por un lado, la corriente neo-gramsciana, iniciada por Robert $\operatorname{Cox}^{48}$ y Stephen Gill ${ }^{49}$, y continuada después por la denominada «Escuela de Amsterdam» de Economía Política Internacional (EPI) centrada en la crítica de la globalización neoliberal, con autores como Kees van der Pijl, Henk Overbeek o Bastian van Appeldorn ${ }^{50}$.

Por otro lado, se encontraría la corriente basada en el pensamiento de Jürgen Habermas, en la que destaca la obra de Andrew Linklater, que desde una perspectiva cosmopolita reafirma la vigencia del imperativo kantiano de reconciliar razón y emancipación ${ }^{51}$. Como Linklater, otros autores cosmopolitas tratarán de reconstruir el proyecto emancipatorio de la modernidad en el nuevo escenario de la globalización, re-formulado en este último caso como «modernidad reflexiva», o "segunda modernidad» ${ }^{52}$. Esa reivindicación, de nuevo, parte de la conceptualización de Jürgen Habermas, según la cual el conocimiento humano se relaciona con tres tipos de «intereses»:

48 Cox, R. W., op. cit., nota 46, y Cox, R. W., Production, Power and World Order. Social Forces in the Making of History, Nueva York, Columbia University Press, 1987. Una perspectiva general en BIELER, A. y Morton, A. D., "A critical theory route to hegemony, world order and historical change: the neo-Gramscian perspective in international relations», Capital \& Class, vol. 28, 2004, núm. 1, pp. 85113; Leysen, A., The Critical Theory of Robert Cox: Fugitive or Guru?, Londres, Palgrave Macmillan, 2008; Ayers, A. J. (ed.), Gramsci, Political Economy and International Relations Theory, Modern Princes and Naked Emperors, Basingstoke, Palgrave Macmillan, 2008; y SANAHUJA, J. A., "Los desafíos de la Teoría Crítica de las Relaciones Internacionales», en AREnAL, C. y SANAHUJA, J. A., op.cit., nota 13, pp. 157-188.

49 GILL, S., "Globalisation, Market Civilization and Disciplinary Neoliberalism», Millennium: Journal of International Studies, vol. 24, 1995, núm. 3, pp. 399-423; GILL, S., "The Global Panopticon?, The Neoliberal State, Economic Life and Democratic Surveillance», Alternatives, vol. 20, 1995, núm. 1, pp. 131-140; y GILl, S. y Cutler, A. (eds.), New Constitutionalism and World Order, Cambridge, Cambridge University Press, 2014.

50 VAN DER PIJL, K., Transnational Classes and International Relations, Londres, Routledge, 1998; OverbeeK, H., «Transnational Historical Materialism in Global Political Economy: Contemporary Theories», en Palan, R., Global Political Economy: Contemporary Theories, Londres, Routledge, 2000, pp. 168-183; Overbeek, H. y Tsolakis, A. (eds.), Globalisation and European Integration: Critical Approaches to Regional Order and International Relations, Londres, Routledge, 2012; OVERBEEK, H. y VAN Appeldorn, B. (eds.), Neoliberalism in Crisis, Londres, Palgrave Macmillan, 2012.

51 Una síntesis en LinKLATER, A., op. cit., nota 28.

52 Diez, T. y SteAns, J., "A useful dialogue? Habermas and international relations», Review of International Studies, vol. 35, 2005, núm. 1, pp. 127-140; ANIEVAS, A., «On Habermas, Marx and the critical theory tradition», en Moore, C. y Farrands, C. (eds.), International Relations Theory and Philosophy: Interpretive Dialogues, Londres, Routledge, 2010, pp. 80-144. 
técnico, relacionado con la comprensión y control de las fuerzas de la naturaleza; práctico, sobre la creación y mantenimiento del orden en la comunidad; y emancipatorio, para identificar y eliminar las limitaciones y constricciones sociales que afectan a los seres humanos ${ }^{53}$. Los tres constituyen conocimiento, y ninguno de ellos está al margen de los valores. Sin el interés emancipatorio, el conocimiento sobre la sociedad estaría incompleto ${ }^{54}$.

Ese propósito praxeológico y normativo explica en parte la importancia que se otorga en estos enfoques al estudio de las estructuras y el poder estructural, y, de nuevo, al problema agente-estructura, considerada uno de los «nudos gordianos» de la disciplina ${ }^{55}$ : ya se ha dicho que el examen de las estructuras históricas concretas permitiría arrojar luz sobre la (mutua) constitución de los actores y la estructura, y cómo esa relación da forma a sus intereses, valores e identidad, y explican su agencia. Pero aquí lo relevante es que ese análisis permitiría identificar qué actores y qué opciones o posibilidades de cambio son inmanentes en cada momento histórico, más allá de utopías o planteamientos voluntaristas ajenos a las fuerzas sociales en pugna y a las posibilidades concretas y reales para la acción colectiva.

Comprometidas también con el cambio se sitúan las teorías feministas de las Relaciones Internacionales, al introducir el propósito emancipador del feminismo: la igualdad entre mujeres y hombres, en cuanto a roles, normas, instituciones, participación y reconocimiento ha de informar una práctica transformadora que, en primer lugar, permita reconstruir las ideas dominantes sobre ciudadanía, que siguen vinculadas al estereotipo de los "gobernantes racionales y justos» o los «hombres en armas» como ejemplos de virtud pública y heroísmo; y que también impulse mejoras concretas en la vida de las mujeres y avanzar en igualdad en una serie de agendas de política: el género y el desarrollo global; la dimensión de género de la globalización; las mujeres y la paz y seguridad; y la ciudadanía y los derechos humanos ${ }^{56}$.

La teoría crítica y el post-estructuralismo, a pesar de tener fundamentos epistemológicos comunes, están separados por una profunda brecha normativa en torno a los propósitos emancipadores de la teoría y del conocimiento. El post-estructuralismo, como señala Noé Cornago, rechaza las grandes narrativas del cambio social enraizadas en la modernidad ilustrada, tanto las que vienen del pasado como su reformulación presente a partir de la constatación histórica de que los grandes proyectos emancipatorios acabaron imponiéndose como prácticas opresivas. Por ello, su propósito será más bien escuchar las distintas formas de contestación que expresan el rechazo a lo

53 Habermas, J., Conocimiento e interés, Valencia, Universidad de Valencia, 1995.

54 Linklater, A., "The achievements of critical theory», en SMITH, S. et al., nota 11, p. 281.

55 Bieler, A. y Morton, A. D., «The Gordian Knot of Agency-Structure in International Relations: A Neo-Gramscian Perspective», European Journal of International Relations, vol. 7, 2001, núm. 1, pp. 5-35; y KNAFO, S., op. cit., nota 24.

56 SJoberg, L. y Tickner, J. A., "Feminist Perspectives on International Relations», en CARLSNAES, W. et al., nota 23, pp. 170-194, y STEANS, J., Gender and International Relations. Issues, Debates and Future Directions, 2. ${ }^{\mathrm{a}}$ ed., Cambridge, Polity Press, 2006. 
existente, y alentar formas de contestación política "post-heroicas» ${ }^{57}$. Para ello, se centrará en cuestionar toda supuesta certeza mediante el análisis crítico de los discursos, dado que estos reflejan la inevitable relación entre saber, poder y subjetividad, desvelando así las múltiples mediaciones que afectan a la comprensión del orden mundial ${ }^{58}$. Ello supone tanto la deconstrucción de las teorías dominantes, como incursiones anárquicas en la cultura popular o los imaginarios colectivos, al estilo de las provocaciones intelectuales de filósofos como Slavoj Žižek.

\section{LA CRÍTICA Y REDEFINICIÓN DE LO UNIVERSAL Y LO HUMANO: POSIBILIDADES DE UN UNIVERSALISMO POST-OCCIDENTAL}

El tercer eje o línea de tensión sería el que contrapone un pretendido universalismo de carácter occidental con la reivindicación de lo específico y lo subalterno, vindicando el particularismo y el relativismo. Como en los ejes anteriores, supone también una pugna entre fundacionalismo y antifundacionalismo, y se trata de un debate que remite a la vieja distinción de la Escuela Inglesa entre el pluralismo y el solidarismo.

Desde el mainstream se ha afirmado - explícita o implícitamente- el carácter universal del conocimiento y prácticas generadas en el seno de la disciplina de las Relaciones Internacionales, así como de sus supuestos epistemológicos, en el marco más amplio de las Ciencias Sociales y, en general, del conocimiento científico. Frente a esas pretensiones universalistas, el social-constructivismo o la teoría crítica ha tratado de demostrar como dicho conocimiento, así como las Ciencias Sociales y la disciplina de las Relaciones Internacionales y sus principales conceptos - Estado, poder, anarquía, polaridad...-, son ontologías históricas y contingentes, "arraigadas» (embedded) en su contexto socio-histórico y civilizacional, que reflejan una determinada hegemonía y contribuyen a su reproducción ${ }^{59}$. Pero ha sido la crítica pos o decolonial la que ha puesto de relieve que, en muchos aspectos, estas actúan como teleologías o constructos hegemónicos o de subalternidad. Esta es quizás su principal contribución crítica: la deconstrucción de la ideología colonial y del «orientalismo» como saberes con una función constitutiva de

57 Cornago, N. y Ferrero, M., «El viaje y las alforjas: alcance y límites de la crítica post-estructuralista de la política mundial», en DE CASTRO, J. L. y ORUETA, G. (coords.), Escritos de internacionalistas en homenaje al Prof. D. Iñaki Aguirre Zabala, Bilbao, Universidad del País Vasco, 2007, pp. 241-268; y CORNAGO, N., "Introducción al postestructuralismo para internacionalistas», en ARENAL, C. y SANAHUJA, J. A., op cit., nota 13, p. 237.

58 Der Derian, J. y Shapiro, M. J. (eds.), International/Intertextual Relations: Post-Modern Readings of World Politics, Lexington, Lexington Books, 1989; Constantinou, C. M., States of Political Discourse: Words, Regimes, Seditions, Londres, Routledge, 2004.

59 Por ejemplo Cox, R. W., «Towards a posthegemonic conceptualization of world order: reflections on the relevancy of Ibn Khaldun", en Rosenau, J. y CzEMPIEL, E. (eds.), Governance without Government: Order and Change in World Politics, Cambridge, Cambridge University Press, 1992, pp. 132-159; o KATZENStEIN, P. J. (ed.), Civilizations in World Politics. Plural and Pluralist Perspectives, Londres, Routledge, 2009. 
identidades, instituciones, normas, concepciones geopolíticas, y a la postre, relaciones de poder ${ }^{60}$.

Según señala Celestino del Arenal, es necesario examinar la genealogía de la disciplina, situar las teorías dominantes en su particular contexto histórico, social e intelectual, e identificar y analizar los mecanismos ideacionales e institucionales en los que se fundamenta la afirmación de determinadas teorías como estándar normativo frente a aquellas que son marginadas o silenciadas ${ }^{61}$. A través de ese examen crítico, esas teorías y el conocimiento que generan y reproducen se "desnaturalizan» y problematizan desvelando su relación con el orden mundial vigente y su papel en la conformación de la narrativa hegemónica de la teoría y la disciplina de las Relaciones Internacionales. En ese proceso, en particular, se ha de cuestionar la directa relación de la disciplina de las Relaciones Internacionales con los intereses, valores y percepciones de Estados Unidos, y de un orden mundial que ese autor denomina "Orden Atlántico» en cuanto es expresión de la hegemonía estadounidense $^{62}$. De ese universalismo expansivo basado en lo occidental serían muestras teorizaciones contemporáneas como las de Francis Fukuyama o Samuel Huntington; mientras que la Escuela Inglesa de la Sociedad Internacional mostraría una aproximación más reflexiva y cautelosa ${ }^{63}$.

La crítica reflexiva que supone el pensamiento decolonial permitiría mostrar como el pretendido universalismo de las teorías dominantes de las Relaciones Internacionales responde, en realidad, a una visión etnocéntrica y «parroquial» que a través de distintos mecanismos políticos, académicos y cognitivos desautoriza y/o condena a los márgenes a otras aportaciones no occidentales, hasta el punto de desautorizar, silenciar o impedir la existencia misma del conocimiento que surge fuera de dichas teorías, e incluso de toda teorización de las Relaciones Internacionales ajena a «lo occidental» ${ }^{64}$. Partiendo de la identificación de lo estadounidense con Occidente, ese etnocentrismo tendría su más concreta y contemporánea expresión en el «americanocentrismo» dominante ${ }^{65}$.

60 En particular, obras fundacionales como FANON, F., Les damnés de la terre, París, Maspero, 1961, o SAID, E., Orientalism, Nueva York, Pantheon, 1978.

${ }^{61}$ AREnal, C., Etnocentrismo y teoría de las Relaciones Internacionales: una visión crítica, Madrid, Tecnos, 2014. Véase también WÆVER, O., «The Sociology of a Not So International Discipline: American and European Developments in International Relations», International Organization, vol. 52, 1998, núm. 4, pp. 687-727; SмIтH, S., «The Discipline of International Relations: Still an American Social Science?», British Journal of Politics and International Relations, vol. 3, 2000, núm. 3, pp. 216-255; BIERSTEKER, T. J., "The Parochialism of Hegemony: Challenges for “American” International Relations», en Tickner, A. B. y WÆVer, O. (eds.), International Relations Scholarship around the World, Londres, Routledge, 2009, pp. 308-327; JørGENSEN, K. et al., nota 27, pp. 107-120.

62 Arenal, C., op. cit., nota 61, 2014, p. 13, 51.

63 O'Hagan, J., Conceptualizing the West in International Relations. From Spengler to Said, Londres, Palgrave, 2002.

64 ACHARYA, A. y BuzAN, B., "Why is there no Non-Western International Relations Theory? An Introduction», International Relations of the Asia Pacific, vol. 7, 2007, núm. 3, pp. 287-312.

65 Un análisis histórico-sociológico en Katzenstein, P. J., "The West as Anglo-America», en ibid. (ed.), Angloamerica and its Discontents. Civilizational Identities beyond East and West, Londres, Routledge, 2012, pp. 1-30. 
Desde mediados del siglo xx este da forma al mainstream de la teoría y la disciplina, cuya «quintaesencia» sería el eje formado por el realismo y el liberalismo-institucionalismo. Este último, en particular, no solo se erige como teoría explicativa de las Relaciones Internacionales, sino como fundamento del proyecto normativo universalista de orden mundial que desde el fin de la Guerra Fría supone el liberalismo: en el terreno político, en apoyo del modelo de democracia liberal que se expande tras la caída del bloque soviético; y en el ámbito económico, como el neoliberalismo y/o "globalismo» que en el ámbito ideacional ha dado alas a la globalización ${ }^{66}$, y a un cosmopolitismo liberal que es difícilmente universalizable por su naturaleza hegemónica y el paulatino retraimiento de Occidente en un mundo de países emergentes en ascenso $^{67}$.

La epistemología reflectivista que emerge desde los años ochenta habría sido, de nuevo según del Arenal «la más seria y radical puesta en entredicho del Orden Atlántico», dada su capacidad para identificar el carácter etnocéntrico de la teoría y de la disciplina ${ }^{68}$. Pero ese cuestionamiento también afecta a su dimensión axiológica e incluso ontológica. Algunas de las teorías que parten de esa epistemología — en particular, la crítica a la colonialidad del saber y el poder - ha llegado a poner en cuestión la propia razón de ser y la existencia de la teoría y de la disciplina de las Relaciones Internacionales, que debiera ser considerada, desde esa perspectiva, una práctica social al servicio de los intereses de poder de Occidente y no, como se percibe a sí misma, como un «ejercicio racional» de elaboración de conocimiento universalmente válido. En ese sentido, la disciplina de las Relaciones Internacionales, como parte del "pensamiento moderno», habría logrado ocultar su naturaleza inherentemente colonial, "naturalizando» la subalternidad de subjetividades y saberes del Sur Global, y negando la agencia del colonizado $^{69}$. Ello reclamaría la asunción de una «epistemología del Sur», en palabras de Boaventura de Sousa, que supere la razón posmoderna y reinterprete el proyecto emancipador desde la experiencia y los saberes del colonizado ${ }^{70}$.

No bastaría, sin embargo, deconstruir y desnaturalizar ese mainstream mostrando su carácter histórico y contingente y su vinculación con las lógicas del poder. Es necesario redefinir «lo internacional» desde las mencionadas epistemologías del Sur recuperando la historicidad no occidental, y construyendo una nueva «sociología global» más plural y diversa, que haga emerger actores, agendas y resistencias que han sido empujadas a los márgenes o a

66 Una exégesis y crítica de este proyecto en PEÑAs, F. J., Hermanos y enemigos. Liberalismo y Relaciones Internacionales, Madrid, La Catarata, 2003.

67 García SEgura, C., «Unidad y pluralismo en la sociedad internacional, el debate contemporáneo entre cosmopolitismo y comunitarismo», en Rodrigo, Á. J. y GARcía SEgura, C. (eds.), Unidad y pluralismo en el derecho internacional público y en la comunidad internacional, Madrid, Tecnos, 2011, p. 105.

68 AREnAL, C., op. cit., nota 61, p. 121.

69 Jerrems, A. y Verdes-Montenegro, F. J., «Movimientos críticos en Relaciones Internacionales. Otras miradas para otras voces», en VVAA, op. cit., nota 24.

70 De Sousa SAntos, B., Una epistemología del Sur: la reinvención del conocimiento y la emancipación global, México, Siglo XXI. 
la subalternidad. En esta dirección opera la indagación sobre la teorización no occidental sobre Relaciones Internacionales ${ }^{71}$. Es el caso, por ejemplo, de los aportes críticos que se han hecho desde América Latina a las Relaciones Internacionales o, en un sentido más amplio, a los Estudios Internacionales, en particular en la teoría del desarrollo. Según algunos teóricos de la decolonialidad, al haber estado abiertos a influencias exteriores, quedarían invalidados como "pensamiento propio», pero puede alegarse en su defensa que ello no les restaría originalidad, significación, o carácter inconformista. Es el caso de las aportaciones a la teoría del desarrollo y la comprensión del sistema internacional como relación entre centro y periferia de Raúl Prébisch y los autores dependentistas, como Fernando Henrique Cardoso o Enzo Faletto; la reflexión de Enrique Dussel sobre las estructuras de dominación del pensamiento; de Aníbal Quijano sobre la colonialidad del poder; la teorización sobre la autonomía de Juan Carlos Puig ${ }^{72}$, y otras aportaciones sobre la identidad latinoamericana y el papel de la integración regional y el regionalismo como instrumento contrahegemónico; o la radical crítica decolonial de Walter Mignolo ${ }^{73}$.

La tarea primordial consistiría en la revisión crítica para «descolonizar» la teoría y la disciplina de las Relaciones Internacionales a partir del reconocimiento de otras perspectivas, tradiciones y teorías ${ }^{74}$, que con ello estaría entrando en un "giro post-occidental $»^{75}$. Pero a partir de ese planteamiento inicial, la teorización crítica se bifurca y hay planteamientos divergentes en cuanto a la posibilidad misma de su reconstrucción, y en tal caso, respecto a la dirección que esta debiera adoptar. Desde posiciones post-estructuralistas o decoloniales se plantea un cuestionamiento radical del universalismo occidental por su papel histórico, su carácter inherentemente colonial e imperialista y su legado de depredación y destrucción de la naturaleza, las sociedades y las subjetividades en nombre de la idea de progreso $^{76}$. Aun más, esa crítica, en muchos aspectos plenamente justificada, sirve de fundamento a la impugna-

71 Tickner, A. B. y Wæver, O., nota 61; Acharya, A. y BuZAN, B. (eds.), Non-Western International Relations Theory, Londres, Routledge, 2010; SHILliAN, R., International Relations and Non-Western Thought: Imperialism, Colonialism and Investigations on Global Modernity, Londres, Routledge, 2011.

${ }^{72}$ KAY, C., Latin American Theories of Development and Underdevelopment, Londres, Routledge, 1989; Martin, L. y Mendieta, E. (eds.), Thinking from the Underside of History. Enrique Dussel's Philosophy of Liberation, Nueva York, Rowman \& Littlefield, 2000; QuiJano, A., Cuestiones y horizontes. Antología esencial, De la dependencia histórico-estructural a la colonialidad/descolonialidad del poder, Selección y Prólogo de Danilo Assís Clímaco, Buenos Aires, CLACSO, 2014; BRICEÑo, J. y Simonoff, A., "La Escuela de la Autonomía, América Latina y la teoría de las Relaciones Internacionales», Estudios Internacionales, vol. 49, 2017, núm. 186, pp. 39-89.

${ }_{73}$ Mignolo, W., The idea of Latin America, Chichester, Wiley-Blackwell, 2008; Escobar, A. y MignoLo, W., Globalization and the Decolonial Option, Londres, Routledge, 2013; Mignolo, W. y WaLsh, C., On Decoloniality, Harrogate, Combined Academic Publishers, 2018.

${ }^{74}$ Gruffyd, B. (ed.), Decolonizing International Relations, Nueva York, Rowman \& Littlefield, 2006.

75 IKedA, J., «The Post-Western Turn in International Theory and the English School», Ritsumeikan Annual Review of International Studies, 2010, núm. 9, pp. 29-44. Véase también Triandafyllidou, A. (ed.), Global Governance from Regional Cultural Perspectives: A Critical View, Oxford, Oxford University Press, 2017.

76 Darby, P., At the Edge of International Relations: Postcolonialism, Gender, and Dependency, Londres, Pinter, 1997; Chowdury, G. y NaIR, S. (eds.), Power, Postcolonialism and International Relations: 
ción radical de la posibilidad misma de cualquier forma de universalismo, por ser necesariamente una manifestación de colonialidad del saber y el poder, y un mecanismo de dominación frente a la defensa fundamental de lo local, lo diverso y en particular de lo que ello representa como resistencia a esa dominación. Pero puede alegarse que ello también conduce necesariamente al relativismo y/o a un multiculturalismo que se sustenta en identidades y discursos autorreferenciales, cerrados a la interacción y al diálogo, y de negación de lo universal y de la alteridad como exponente de una realidad social y humana que al tiempo que diversa, tiene también dimensiones y retos universales.

Frente a ello, diversas teorías, como la EPI crítica, el cosmopolitismo neokantiano, e incluso determinados feminismos decoloniales afirman la posibilidad y necesidad de un nuevo universalismo no occidental. En particular, desde la perspectiva cosmopolita de Jürgen Habermas y de autores que siguen su estela como Andrew Linklater, se ha afirmado que la teoría de las Relaciones Internacionales debería apelar a valores universales de libertad y justicia, aunque estos se redefinan en cada momento histórico. Ello supone asumir un universalismo mínimo, contingente, transitorio y respetuoso de la diversidad, como fundacionalismo normativo básico que parte del diálogo entre los valores universales de igualdad y justicia y las circunstancias locales e históricas específicas con las que esos valores y aspiraciones se redefinen, reinterpretan y resignifican. La tradición humanista occidental, de cuyas raíces bebe también la teoría de las Relaciones Internacionales, puede contribuir a ello. Según la filósofa Marina Garcés, «la tradición humanista occidental debe abandonar el universalismo expansivo y aprender a pensarse desde un universal recíproco» ${ }^{77}$. Y a continuación plantea "la necesidad de que la crítica al humanismo histórico y a sus modelos universales no borre en nosotros la capacidad de vincularnos con el fondo común de la experiencia humana [...] más que ser negados, el humanismo y el legado cultural europeo necesitan ser puestos en su lugar: un lugar, entre otros, en el destino común de la humanidad [...]. Esto implica no solo criticar sino también dejar tanto el universalismo expansivo como el particularismo defensivo, para aprender a elaborar universales recíprocos ${ }^{78}$.

Basándose en parte en la teoría de la acción comunicativa de Jürgen Habermas, estas perspectivas reafirmarían la capacidad de las personas para alcanzar consensos a través de la deliberación, la argumentación y el debate racional. Esa deliberación permitiría construir una ética del discurso universalista capaz de reconocer e incorporar las diferencias a través de una racionalidad inclusiva que actúa, a su vez, como mecanismo de legitimación democrática para una gobernanza global ${ }^{79}$. Todo ello, con el propósito de vis-

\footnotetext{
Reading Race, Gender and Class, Londres, Routledge, 2004; Doty, R. L., Imperial Encounters: The Politics of Representation in North-South Relations, Minneapolis, University of Minnesota Press, 1996.

77 GARcés, M., Nueva ilustración radical, Barcelona, Anagrama, 2017, p. 67.

78 GARcÉs, op. cit., nota 77, pp. 68-69.

79 RISSE, T., «Let's Argue!: Communicative Action in World Politics», International Organization, vol. 54, 2000, núm. 1, pp. 1-39; LinKLATER, A., «The politics of dialogical communities and the civilis-
} 
lumbrar formas alternativas de comunidad política que posibiliten la emancipación humana basadas en un universalismo ético arraigado en valores surgidos de un diálogo sin barreras. Desde esta posición, esta aproximación crítica a la teoría de las Relaciones Internacionales abre vías para construir formas más inclusivas y abiertas de comunidad política y un universalismo post-hegemónico o post-occidental cargado de posibilidades de emancipación. Para ello, la comunidad política habría de experimentar tres transformaciones: reconocer la necesidad de universalizar determinados principios políticos y morales; reducir la desigualdad material; y reconocer la diversidad humana. Según Andrew Linklater «La Teoría Crítica mantiene su fe en el proyecto de la ilustración y defiende el universalismo en su ideal de un diálogo abierto no solo entre los conciudadanos, sino más radicalmente, entre todos los miembros de la raza humana» ${ }^{80}$. Este es en muchos aspectos el proyecto explícitamente normativo asumido también por los exponentes tardíos de la Escuela Inglesa de la Sociedad Internacional, conscientes tanto de la inviabilidad de un orden internacional basado en los valores occidentales, como de las limitaciones del pluralismo en un mundo globalizado y transnacionalizado, y por lo tanto necesitado de acuerdos y normas comunes amparadas por la legitimidad que solo puede emanar del acuerdo surgido de una "conversación global» sin exclusiones basada en la deliberación racional.

Como señala Andrew Hurrell, ello implicaría redefinir la noción de pluralismo, desvinculándola de los Estados-nación y del principio de soberanía, y centrándola en los derechos y aspiraciones de las personas; supone también dejar atrás el etnocentrismo y reconstruir el universalismo a partir de un reconocimiento más amplio de la diversidad. El necesario orden cosmopolita habría de estar basado en una nueva conexión entre el cosmopolitismo moral y el cosmopolitismo político. Para ello, según Hurrell, son necesarios tres elementos: la "accesibilidad moral», concepto que alude a un universalismo basado en el razonamiento moral sobre el significado común de la justicia; la autoridad institucional, que permita conectar la razón moral con la práctica política, a través de procesos deliberativos racionales y de los marcos institucionales adecuados que los hagan posibles, lo que implica diseñar formas de democracia deliberativa a escala regional y/o global; y la agencia política, con Estados y organismos internacionales que puedan actuar conforme a esa razón cosmopolita y a principios universalistas, y sean así los vehículos adecuados para la acción ciudadana ${ }^{81}$.

Los tres ejes o líneas de tensión que se han examinado en este artículo sitúan la teoría de las Relaciones Internacionales ante múltiples desafíos: ontológicos, epistemológicos, y praxeológicos o normativos. Confirman que, desde la abstracción y el rigor metodológico exigible a la teoría, esta nos ha-

ing process», Review of International Studies, vol. 31, 2005, núm. 1, pp. 141-154; y HelER, M., Jürgen Habermas y el proyecto moderno. Cuestiones de la perspectiva universalista, Buenos Aires, Biblos, 2007, pp. 93-105

${ }^{80}$ Linklater, A., "The achievements of critical theory», en SMith, S. et al., op. cit., nota 11, p. 296.

81 Hurrell, A., op. cit., nota 28, pp. 300-317. 
bla de los retos concretos de nuestra época: de una «modernidad reflexiva» que exige a la disciplina una mirada crítica sobre su propia definición y sentido de lo universal, y en no pocos aspectos, una «reconstrucción» que supone revisar las convenciones y límites asumidos por la disciplina y sus enfoques dominantes. Como se ha señalado, frente a la rigidez del racionalismo y los confines impuestos a las Ciencias Políticas o las Relaciones Internacionales se ha ido abriendo paso una mayor atención a la Historia, la Sociología o la Filosofía. A su vez, el giro epistemológico hacia la reflexividad, a través del post-estructuralismo, la teoría crítica o las teorías feministas estarían abriendo paso a otros sujetos y vivencias, y al conocimiento, agendas y métodos de la Antropología, la Estética o los Estudios Culturales.

Finalmente, esa mirada reflexiva ha permitido resituar la teoría de las Relaciones Internacionales y el conjunto de la disciplina en un contexto más amplio de contestación y repolitización relacionadas con valores, principios e instituciones sociales sobre las que de una forma u otra se asienta el orden internacional. En ese escenario, desde la interacción de la academia y los actores sociales pueden surgir las ideas que sustenten una «modernidad reflexiva» que permita reconstruir el proyecto de emancipación humana de la ilustración. En esas encrucijadas se situaría la reflexión y conocimiento que la disciplina y la teoría de las Relaciones Internacionales estaría llamada generar.

\section{RESUMEN \\ REFLEXIVIDAD, EMANCIPACIÓN Y UNIVERSALISMO: CARTOGRAFÍAS DE LA TEORÍA DE LAS RELACIONES INTERNACIONALES}

Desde su giro post-positivista de los años ochenta del siglo xx, la teoría y la disciplina de las Relaciones Internacionales se ha tornado más plural y diversa, y su cartografía se puede trazar a partir de tres ejes o líneas de tensión: la primera, de índole epistemológica, tiene al racionalismo y al reflectivismo radical como polos extremos, con un terreno intermedio en el que se sitúa el constructivismo social, como racionalismo moderado, o la teoría crítica neo-gramsciana; el segundo eje, de índole praxeológico-normativo, se organiza en torno a la posibilidad y deseabilidad del cambio; el tercero gira en torno a la definición de lo universal frente a la diversidad, y la posibilidad o negación de un universalismo postoccidental. En esas tres divisorias, a su vez, subyace un eje de tensión entre fundacionalismo y antifundacionalismo, tanto en el ámbito epistemológico como normativo.

Palabras clave: teoría de las Relaciones Internacionales, reflectivismo, racionalismo, epistemología, fundacionalismo, universalismo.

\section{ABSTRACT \\ REFLEXIVITY, EMANCIPATION AND UNIVERSALISM: CARTOGRAPHIES OF THE THEORY OF INTERNATIONAL RELATIONS}

Since his post-positivist turn of the Eighties of the 20st Century, both the theory and discipline of International Relations has become more plural and diverse, and its cartography can be drawn from three axes or lines of tension: the first one, in the epistemological realm, has radical rationalism and reflectivism as extreme poles, with social constructiv- 
ism, as moderate rationalism, and neo-Gramscian critical theory in the middle ground; the second axis, of praxeological-normative nature, is organized around the possibility and desirability of change; the third one address the definition of universality versus diversity, and the possibility or negation of a post-Western universalism. All of them also entail divergences between foundationalism and anti-foundationalism, both in the epistemological and normative realm.

Keywords: International Relations theory, reflectivism, rationalism, epistemology, foundationalism, universalism. 